\title{
Canadian EEG Standards: A Quality Issue
}

Can. J. Neurol. Sci. 2002; 29: 205

The landmark article on Electroencephalography (EEG) Standards by the Canadian Society of Clinical Neurophysiologists (CSCN) (this issue) describes a signal achievement that arrives at an opportune time. These minimal standards developed by their committee respond to two confluent trends: 1) a growing public awareness of, and demand for quality, and 2) the emergence of cost effectiveness as a barometer of value by ministries of health.

Growth of modern neuroimaging techniques has substantially sharpened our diagnostic capability, but it has also created the false belief by the public and many physicians that MRI or CT offers the premier solution to virtually all clinical neurological problems. However, high quality EEG affords a functional perspective to several areas of clinical neuroscience. Relevant data to some of these are outlined as follows.

\section{EPILEPSY}

\section{The Diagnosis}

- Epileptic discharges (spikes) appear in a single awake recording of $50 \%$ of persons with epilepsy; ${ }^{1}$ this proportion rises to $80-85 \%$ if sleep is included. This compares to two to three percent of patients with non-epileptic conditions. ${ }^{2}$

\section{Syndrome Identification}

- Seizure semiology and EEG play principal roles in establishing the epilepsy syndrome that seizures represent. ${ }^{3}$ Syndrome identification is requisite for management decisions and prognosis.

\section{Epilepsy Surgery and Seizure Localisation}

- Focal interictal spikes on an outpatient EEG may help identify candidates for surgery. ${ }^{4-6}$

\section{Driving}

- According to Physician's Guide to Driver Examination of the Canadian Medical Association, evaluation of a patient with a single spontaneous seizure or with seizures exclusively in sleep specifically includes EEG. EEG may also aid in the evaluation of other epilepsy questions related to driving.

\section{DEMENTIA}

- EEG abnormalities may appear earlier than those of neuroimaging. ${ }^{7}$

- Prognosis correlates well with severity of EEG abnormalities. ${ }^{8,9}$

- A normal EEG suggests either depression masquerading as dementia or the slowly progressive frontal temporal dementia of Pick's disease.

\section{Comatose STATES}

- EEG offers best laboratory evaluation of cortical function in comatose patients. ${ }^{10}$

- Its patterns help establish: a) principal etiology, and b) prognosis for survival. ${ }^{11}$
- EEG detects recurrent, clinically occult seizures including nonconvulsive status epilepticus. ${ }^{12}$

The foregoing samples are all weighty matters requiring exemplary technological performance and interpretation. Awareness of development of the CSCN guidelines has stimulated interest in neurology residents to take the EEG examinations offered by the CSCN.

Thus, the standards should serve as a touchstone for a renewed and augmented interest in clinical neurophysiology. They have placed a premium on high quality performance and interpretation of EEG.

Warren T. Blume

London, Ontario

\section{REFERENCES}

1. Binnie CD, Stefan H. Modern electroencephalography: its role in epilepsy management. Clin Neurophysiol 1999; 110: 1671-1697.

2. Ajmone Marsan C, Zivin LS. Factors related to the occurrence of typical paroxysmal abnormalities in the EEG records of epileptic patients. Epilepsia 1970; 11: 361-381.

3. Blume WT. Diagnosis and treatment of epilepsy. Can J CME 2001; 13: $159-177$.

4. Blume WT, Borghesi JL, Lemieux JF. Interictal indices of temporal seizure origin. Ann Neurol 1993; 34: 703-709.

5. Cendes F, Li LM, Watson C, et al. Is ictal recording mandatory in temporal lobe epilepsy? Not when the interictal electroencephalogram and hippocampal atrophy coincide. Arch Neurol 2000; 57: 497-500.

6. Walczak TS, Jayakar P. Interictal EEG. In: Engel J, Jr. Pedley TA. (Eds.) Epilepsy: A Comprehensive Textbook, Volume 1. Philadelphia, PA: Lippincott-Raven Publishers, 1997: 831-848.

7. Merskey H, Ball MJ, Blume WT, et al. Relationships between psychological measurements and cerebral organic changes in Alzheimer's disease. Can J Neurol Sci 1980; 7: 45-49.

8. Rae-Grant AD, Blume WT, Lau C, et al. The EEG in alzheimer type dementia: lack of progression with sequential studies. Can J Neurol Sci 1986; 13:(4) Suppl: 407-410.

9. Kaszniak AW, Fox J, Gandell DL, et al. Predictors of mortality in presenile and senile dementia. Ann Neurol 1978; 3: 246-252.

10. Young GB. The EEG in coma. J Clin Neurophysiol 2000; 17: 473485.

11. Young GB, Kreeft JH, McLachlan RS, DeMelo J. EEG and clinical associations with mortality in comatose patients in a general intensive care unit. J Clin Neurophysiol 1999; 16: 354-360.

12. Towne AR, Waterhouse EJ, Boggs JG, et al. Prevalence of nonconvulsive status epilepticus in comatose patients. Neurology 2000; 54: 340-345.

From the London Health Sciences Centre, The University of Western Ontario, London, Ontario, Canada.

Reprint requests to: Warren T. Blume, London Health Sciences Centre - University

Campus, The University of Western Ontario, 339 Windermere Road, London, Ontario,

Canada, N6A5A5 